\title{
Integrative paleontological and geochemical study of the microfossil Polysphaeroides filiformis and its implication for deep time cyanobacterial evolution
}

\author{
CATHERINE F. DEMOULIN ${ }^{1}$, MARIE CATHERINE
}

SFORNA $^{1}$, YANNICK J. LARA ${ }^{1}$, CORENTIN C. LORON ${ }^{1}$, YOHAN CORNET ${ }^{1}$, REMI TUCOULOU TACHOUERES ${ }^{2}$, DANIEL GROLIMUND ${ }^{3}$, DARIO FERREIRA SANCHEZ ${ }^{3}$, AHMED ADDAD ${ }^{4}$, ALEXANDRE FADEL ${ }^{4}$, PHILIPPE COMPÈRE $^{1}$ AND EMMANUELLE J. JAVAUX ${ }^{1}$

${ }^{1}$ Université de Liège

${ }^{2}$ European Synchrotron Radiation Facility

${ }^{3}$ Swiss Light Source

${ }^{4}$ Univ. Lille, CNRS

Presenting Author: cdemoulin@uliege.be

Cyanobacteria, a major phylum among the Bacteria domain, played an important role in the evolution of early Life and Earth by strongly changing the redox conditions of early ecosystems, since at least the Great Oxidation Event (GOE, $\sim 2.4 \mathrm{Ga}$ ). Despite their importance, their unambiguous fossil record is scarce. Only three microfossil taxa are interpreted as cyanobacteria with certainty. Therefore, it is essential to characterize new biosignatures of cyanobacteria for a better identification of their microfossil counterparts. Newly identified fossils from welldated geological successions will then enable a better calibration of molecular clocks of cyanobacteria, thereby allowing a better understanding of their diversification, and their role in Earth and life evolution.

Here we studied the morphology, ultrastructure, chemical composition and metals distribution of one microfossil taxon identified as a cyanobacterium, Polysphaeroides filiformis, from the $\sim 1$ Ga Mbuji-Mayi Supergroup (Congo Basin, DR Congo). $P$. filiformis consists of spheroidal vesicles surrounded by a common branching sheath. The observation of the microfossil ultrastructure reveals a trilaminar structure for the sheath. The $\mathrm{SR}-\mathrm{XRF}$ detection of homogeneous distribution of $\mathrm{Ni}$ within intracellular inclusions (ICIs; fossilized cell content) combined to XANES at the Ni K-edge data highlight the phototrophic nature of $P$. filiformis. The combination of microscopy, spectroscopy and SR-analyzes allows an unambiguous interpretation of $P$. filiformis as a branched and multiseriate phototroph organism, most probably, a cyanobacterium. Moreover, the specific distribution of other metals in ICIs, such as $\mathrm{Co}$ and $\mathrm{Cu}$, suggests a great potential of these elements as biosignatures. 